\title{
Research of Chatter Suppression in Turning Operation with Process Damping using Stability Lobe Diagram
}

\author{
R. Samin, M.Z. Nuawi, F.A. Azmi, S.M. Haris, J.A. Ghani
}

\begin{abstract}
This paper presents a chatter detection technique based on the stability of the measured $R a$ and $R z$ values of process damping and surface roughness in low cutting speed activities. In practice, process damping during machining procedures is hard to predict and identify due to the model and technique of limitation. The impact of cutting conditions on process damping in turning with P20 steel pre-hardened metal in terms of cutting velocity, feed rate and cutting depth was explored by the Stability Lobe Diagram method. A CNC turning machine was used in dry turning procedures with carbide insert. The highest and minimum value of natural frequencies and damping ratios were evaluated by modal testing and the stability lobe diagram analysis was applied. It is concluded that in the same region of the Stability Lobe Diagram, the chatter and measured surface roughness values were correlated and shown to have strong consensus.
\end{abstract}

Keywords: Chatter vibration, modal analysis, process damping, stability lobe diagram, turning.

\section{INTRODUCTION}

Machining research increases productivity, which, in turn, can be achieved by selecting optimum cutting conditions. Turning processes have a significant impact on the rate of material removal, and hence productivity, however, it is constantly restricted by chatter vibrations. During machining, the stability occurs where the stable depth of cut is high and high-speed machining can be used. Meanwhile, in low-speed machining, the procedure damping might show a critical impact on stability. Process damping occurs due to tool penetration at low cutting speeds and is perceived as having a higher stable cutting depth due to the impact of process damping. Low cutting speeds must be utilized as a part of numerous applications because of speed impediments on the machine, or for material with low machinability which is regularly utilized as a part of the aerospace industry, for example, titanium. Moreover, in situations where high depth of cut must be utilized out of necessity, for instance, in flank milling of turbine engine blades, low

Revised Manuscript Received on September 14, 2019.

R. Samin, Dept. of Mechanical and Material Engineering, Faculty of Engineering and Built Environment, Universiti Kebangsaan Malaysia, Bangi, Selangor, Malaysia and Dept. of Mechanical and Manufacturing Engineering, Faculty of Engineering, Universiti Putra Malaysia, Serdang, Selangor, Malaysia. (Email: zali@upm.edu.my)

M.Z. Nuawi, Dept. of Mechanical and Material Engineering, Faculty of Engineering and Built Environment, Universiti Kebangsaan Malaysia, Bangi, Selangor, Malaysia.

F.A. Azmi, German-Malaysian Institute, Jalan Ilmiah, Taman Universiti, 43000 Kajang, Selangor, Malaysia.

S.M. Haris, Dept. of Mechanical and Material Engineering, Faculty of Engineering and Built Environment, Universiti Kebangsaan Malaysia, Bangi, Selangor, Malaysia.

J.A. Ghani, Dept. of Mechanical and Material Engineering, Faculty of Engineering and Built Environment, Universiti Kebangsaan Malaysia, Bangi, Selangor, Malaysia. cutting speeds must be utilized to balance out the procedure. Stable depth of cut at low speeds is ordinarily achieved by experimentation since there are few techniques to gauge the process damping sum for a cutting session.

The effect of low cutting speed is examined in this paper by using low cutting depth and low feed rate. A good stability rate is obtained by finding where the stability of the cutting is sustained in conjunction with other low-speed parameters. Chatter is a self-excited vibration that appears during the machining procedure and creates a recurring quality and productivity weakness to the part. There are two main categories of chatter: primary and secondary. Primary chatter is the result of the cutting process, to begin with. Secondary chatter might occur with waviness generated on the machined workpiece surface. Unstable vibration of the chatter leads to a wavy surface finish that can lead to machine wear, tool failure, or harm [1]. The regenerative effect of chatter is a usual mode of self-excited vibration. During the cutting method, in [2] indicated that chatter can be discovered in certain combinations of cutting axial depth and spindle speed. The boundary between a chatter-free stable cut and an unstable one with chatter that can be exhibited in SLD is a relationship between the two cutting parameters.

Under certain conditions, the SLD from the cutting tool system, the workpiece and the machine tooling is constantly changing and it is potently difficult to obtain forecasts and correct parameters in order to confirm stable machining. The chatter identification technique does not require SLD identification, but it is possible to use statistical signal analysis [3]. In [4] developed a method that shows SLD displays and the boundary between unstable processes and machining operations free from chatter, where the function of cutting speed is acted by depth of cut. Machining parameters with chatter-free combinations are selected using the designated diagrams.

Some researchers relate the stability of the machining with the vibration of the chatter using surface roughness [5], [6]. In [7] recognized factors that have a significant impact on the responses and predicted the response value under the optimum parameters. By applying cryogenic condition (LN2) in this turning method, experimental findings indicate that the minimum and maximum $R a$ values were attained at $0.888 \mu \mathrm{m}$ and $2.889 \mu \mathrm{m}$ respectively. Chatter appearance on machine tools is catastrophic as it prevents the necessary surface finishes from being produced and reduces the life of tools and mechanical parts [8]. The objective of this study 


\section{RESEARCH OF CHATTER SUPPRESSION IN TURNING OPERATION WITH PROCESS DAMPING USING STABILITY LOBE DIAGRAM}

was to explore the impacts on cutting parameters of chatter stability and surface roughness and to determine whether a correlation existed between them. In this paper, a stability lobe diagram can be used to address the issue of chatter instability for expected surface quality.

\section{METHODOLOGY}

\section{A. Materials and Equipment}

This paper used Mazak 200MY CNC machine with a maximum speed of $4500 \mathrm{rpm}$, a maximum pressure of 86 $\mathrm{KN}$ and $5 \mathrm{~kW}$. The cutting parameters were carried out as shown in Table I for cutting speed, feed rate and depth of cut. The material of the workpiece used is P20 pre-hardened tool steel with the diameter dimension of $31 \mathrm{~mm}$ and length of $150 \mathrm{~mm}$. The length to diameter ratio for this experiment is 4.84:1, which falls within an acceptable range for machining with a chuck and a tailstock at both ends of the workpiece to prevent deflection during cutting. P20 steel is the most widely used mould steel as opposed to various products used for mould steel, it has numerous points of concern. It is widely used for the production of injection moulds and compression moulds. Hardness material P20 is approximately $34 \mathrm{HRC}$ and is unnecessary for subsequent heat treatments. P20 steel contains 0.30 to 0.40 percent carbon, 0.35 percent sulphur, pre-hardened moulded steel, also known as abrasive-resistant, tougher and stronger material, which allows longer life. P20 steel is sometimes used to make long shaft vehicles and live axles that used torque transfer and sliding contact. The proportion of chromium and nickel can increase the strength and hardness of P20 steel. Containing 1.00 percent of high nickel content, it is specially adapted to ensure the precise homogeneity of the shaft structure, excellent polishing tolerance, good corrosion resistance and excellent machinability.

Table- I: Experimental procedure

\begin{tabular}{|c|c|c|c|}
\hline $\begin{array}{l}\text { 1. Exp. } \\
\text { 2. Run }\end{array}$ & $\begin{array}{c}\text { 3. Cutting } \\
\text { Speed, } \\
\text { 4. } \boldsymbol{V}_{\boldsymbol{c}}(\mathbf{m} / \mathbf{m i n})\end{array}$ & $\begin{array}{c}\text { 5. Feed Rate, } \\
\mathbf{6 .} \boldsymbol{f}(\mathbf{m m} / \mathbf{r e v})\end{array}$ & $\begin{array}{c}\text { 7. Depth of } \\
\text { Cut, } \\
\text { 8. } \boldsymbol{d} \text { ( mm })\end{array}$ \\
\hline 1 & 50 & 0.05 & 0.2 \\
\hline 2 & 75 & 0.05 & 0.2 \\
\hline 3 & 100 & 0.05 & 0.2 \\
\hline 4 & 100 & 0.04 & 0.2 \\
\hline 5 & 75 & 0.09 & 0.2 \\
\hline 6 & 50 & 0.04 & 0.2 \\
\hline 7 & 100 & 0.05 & 0.2 \\
\hline 8 & 100 & 0.03 & 0.5 \\
\hline 9 & 100 & 0.05 & 0.4 \\
\hline
\end{tabular}

\section{B. Cutting Tool Selection}

The selection of cutting tools for machining is important to avoid wear or defect of the cutting tool and insert for surface roughness measurement. The PVD carbide inserts were used with ISO coding of CNMG 120404-UF by YG and the tool holder by E-Chain with ISO coding of ENLNR2525M12. The coating of the PVD insert was titanium aluminum nitride coated (TiAlN). Although subject to exceptionally elevated temperatures, this sort of instrument bits retains the hardness and therefore is recommended where there is very high heat generation. It also does not blunt readily at elevated temperatures or high friction.

\section{Surface Roughness Measurement}

This paper uses arithmetic average of the roughness profile, $R a$ and mean depth of profile surface roughness, $R z$ values. The experimental procedure was carried out to obtain measurements at four position points around the workpiece circumference. MarSurf Psi was used to measure the surface roughness with a cut-off length of $2.5 \mathrm{~mm}$. The $R a$ value is the commonly utilized roughness parameter and most appropriate for observing the consistency of the machining procedure [5], [9]-[12]. In [13] found that no microstructural changes were observed under the machined surface of the dimpled region and surface roughness $(R a)$ for both the dimple and the non-dimpled surfaces in the dimple manufacturing process.

\section{Experimental Procedure}

This paper presents the experimental configuration used as shown in Fig. 1. Fig. 1(a) indicates a numerically controlled (NC) program for the CNC turning device. Fig. 1(b) shows the tool holder and insert were attached on CNC machine with the single-axial and tri-axial accelerometers on the CNC machine and on tool holder respectively. The ranges of cutting parameters include cutting speeds of 50 to $100 \mathrm{~m} / \mathrm{min}$, constant feed rate of $0.1 \mathrm{~mm} / \mathrm{rev}$ and cutting depth of 0.5 to $1.0 \mathrm{~mm}$.

In this study, an effort was made to determine if the cutting parameters could affect the response of the vibration signal in the arithmetic mean surface roughness $(R a)$ and mean profile surface roughness $(R z)$ values obtained from the experiments. Fig. 1(c) shows the experimental modal analysis was done with an impact hammer and LMS Scadas system and LMS Test.Lab Impact Testing software. Fig. 1(d) shows the roughness of the surface was evaluated after cutting. The impact test was obtained in the frequency domain data from LMS DAQ, then the data were exported in text format. The $R a$ and $R z$ values were measured by averaging $R a$ and $R z$ values at four different position points around the workpiece circumference. The data were exported and processed with LMS Test.Lab Navigator data calculator worksheet.

\section{E. Modal Testing}

Modal testing is required to predict the stability of a cutting tool system to obtain its dynamic properties and FRF's [5], [6]. In [14] performed the impact testing by a modal hammer, FRF was monitored by CUTPRO software and data fitted modal parameters such as natural frequency, mass, stiffness and damping ratio were obtained. In this paper, the experimental modal analysis was used to impact hammer, accelerometer and LMS Scadas Testing system.

The impact hammer model is Brüel \& Kjær type 8206002 with a sensitivity of $10 \mathrm{mV} / \mathrm{N}$. Another accelerometer was used as a reference by Dytran 3145A, single-axial accelerometer with a sensitivity of $104.3 \mathrm{mV} / \mathrm{g}$ and mounted on the cutting tool holder. The impact force signal was evaluated using the software and data acquisition system LMS Test. Lab, LMS Scadas Mobile with four channels to

$$
\begin{aligned}
& \text { Blue Eyes Intelligence Engineering } \\
& \text { \& Sciences Publication }
\end{aligned}
$$$$
\text { Published By. }
$$ 
achieve the modal parameters. Fig. 2(a) shows that the accelerometer is positioned at the back end of the workpiece and the impact hammer testing is performed at the other end of the workpiece. As for the cutting tool, the accelerometer is placed at the end body of the tool holder and the impact hammer testing is done on the carbide insert holder at the end of the cutting tool as shown in Fig. 2(b). Siemens LMS Test. Lab was used to assess the cutting tool and workpiece's natural frequencies, dynamic stiffness and structural damping ratio. The damping coefficient $\zeta(\%)$ and frequency $(\mathrm{Hz})$ were measured and recorded as shown in Table II.

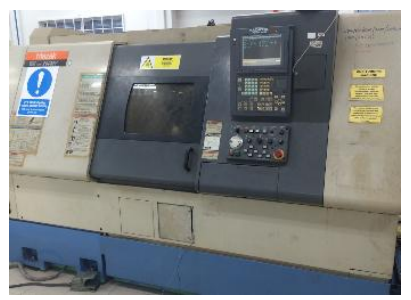

a) CNC machine

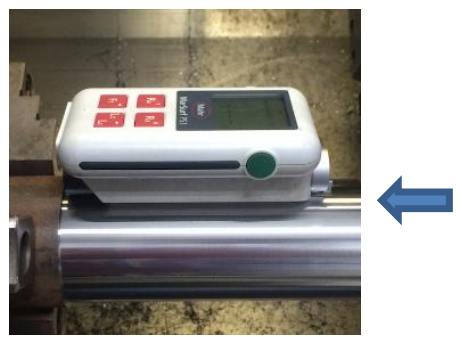

d) Work piece and surface roughness measurement

Fig. 1.Experimental equipment.

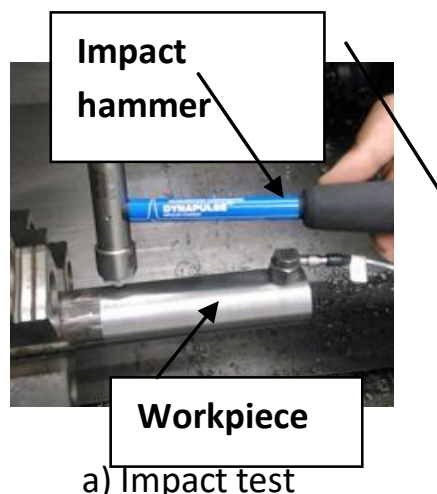

for work piece

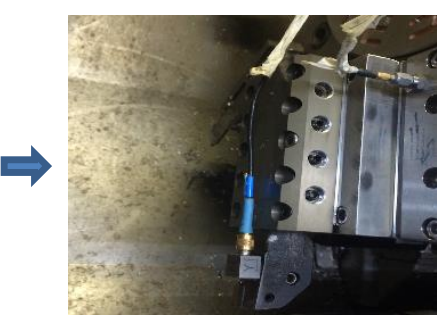

b) Cutting tool

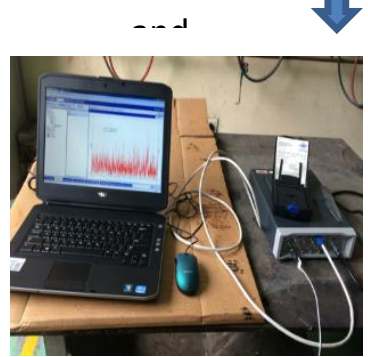

c) LMS Test.Lab impact testing system

The result follows the value acquired by the interaction of the measurement apparatus and the experimental material. The frequency and damping coefficients generated by the LMS software were used for the SLD analysis. The cutting parameters such as the workpiece diameter, cutting speed, spindle speed, feed rate and depth of cut were used. Fig. 3 and 4 show experimental measured modal impact test parameters.

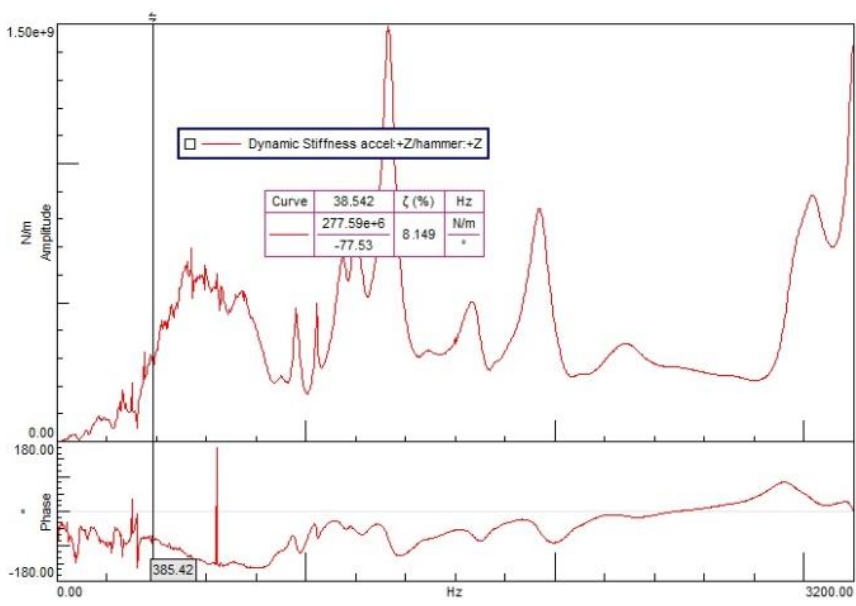

Fig. 3: Modal parameters for workpiece

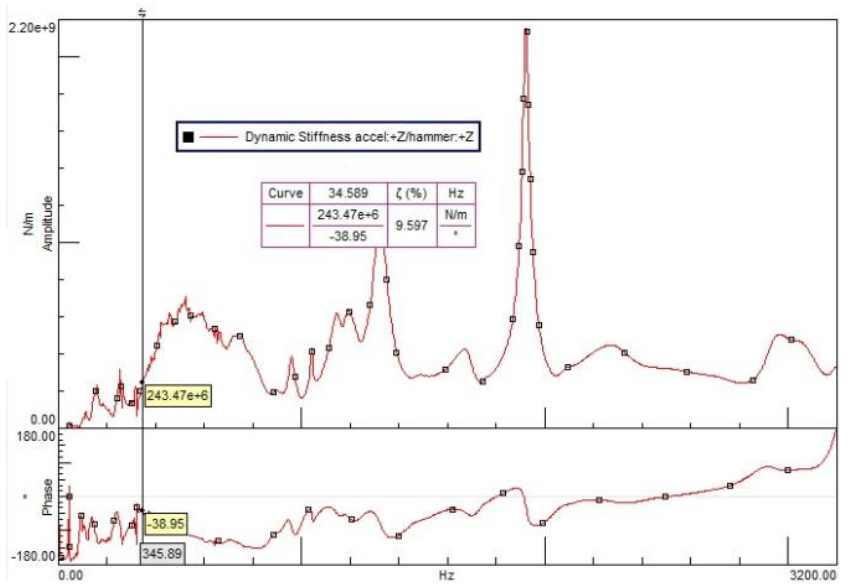

Fig. 4.Modal parameters for cutting tool.

\section{RESULTS AND DISCUSSION}

Surface roughness measurement values are shown in Table III for nine runs of experiments. In Fig. 5, the best value of $R a$ is obtained at cutting run 9 (cutting speed 100 $\mathrm{m} / \mathrm{min}$ and feed rate $0.05 \mathrm{~mm} / \mathrm{min}$ ) where the value is 1.06 $\mu \mathrm{m}$ which resulting the best surface finish while the poorest values of the $R a$ is obtained at cutting run 6 (cutting speed $50 \mathrm{~m} / \mathrm{min}$ and feed rate $0.04 \mathrm{~mm} / \mathrm{min}$ ) where the value is 5.9 $\mu \mathrm{m}$. The difference between the best and poorest reading is $4.84 \mu \mathrm{m}$. The percentage of difference is at $82.03 \%$.

Table- III: Results of surface roughness

Fig. 2.Impact testing for experimental modal analysis.

Table- II: Impact hammer test result

\begin{tabular}{|c|c|c|}
\hline Item & \multicolumn{2}{|c|}{ Cutting Tool } \\
\hline & $\begin{array}{c}\text { Damping } \\
\text { Ratio, } \boldsymbol{\zeta}(\%)\end{array}$ & $\begin{array}{c}\text { Natural } \\
\text { Frequency }(\boldsymbol{H z})\end{array}$ \\
\hline Workpiece & 9.597 & 34.589 \\
\hline Cutting tool & 8.509 & 35.083 \\
\hline
\end{tabular}

\begin{tabular}{|c|c|c|}
\hline Run No. & $\boldsymbol{R} \boldsymbol{a}(\boldsymbol{\mu m})$ & $\boldsymbol{R} \boldsymbol{z}(\boldsymbol{\mu} \mathbf{m})$ \\
\hline 1 & 1.38 & 9.40 \\
\hline 2 & 1.40 & 9.80 \\
\hline 3 & 1.25 & 11.5 \\
\hline 4 & 2.53 & 17.1 \\
\hline 5 & 2.45 & 16.9 \\
\hline
\end{tabular}

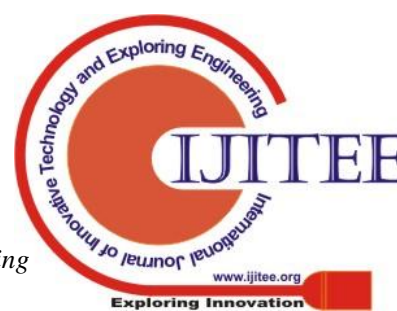




\begin{tabular}{|l|l|l|}
\hline 6 & 5.90 & 33.2 \\
\hline 7 & 3.85 & 24.1 \\
\hline 8 & 1.40 & 8.96 \\
\hline 9 & 1.06 & 6.90 \\
\hline
\end{tabular}

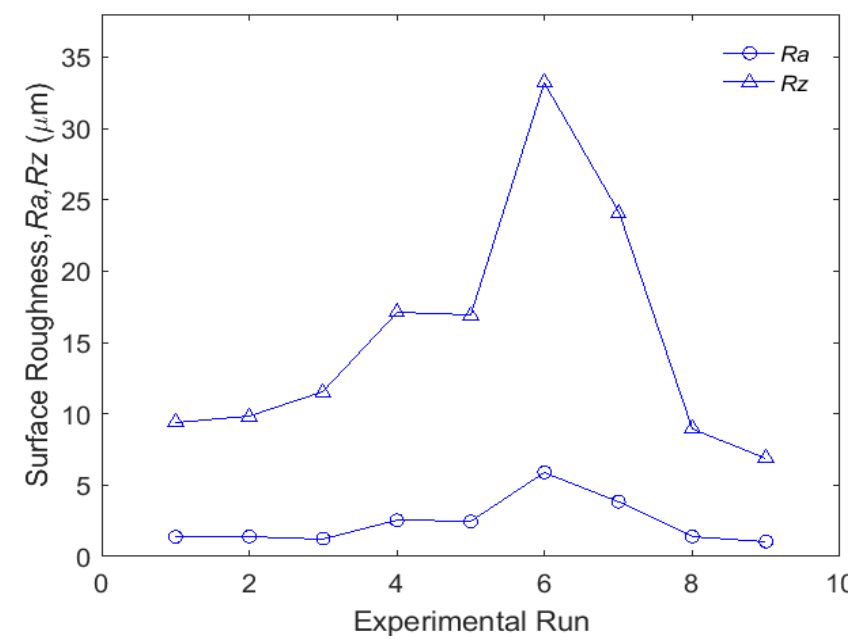

Fig. 5.Data for surface roughness, $R a$ and $R z$.

To simulate perfect stability for material cutting, a stability lobe diagram was used as shown in Fig. 6 and 7. Cutting speed and depth of cut were evaluated and plotted; the outcome was then meshed with the diagram of the program. The program used is an open source Wolfram demonstration project [15]. The parameters that are used are from the modal testing.

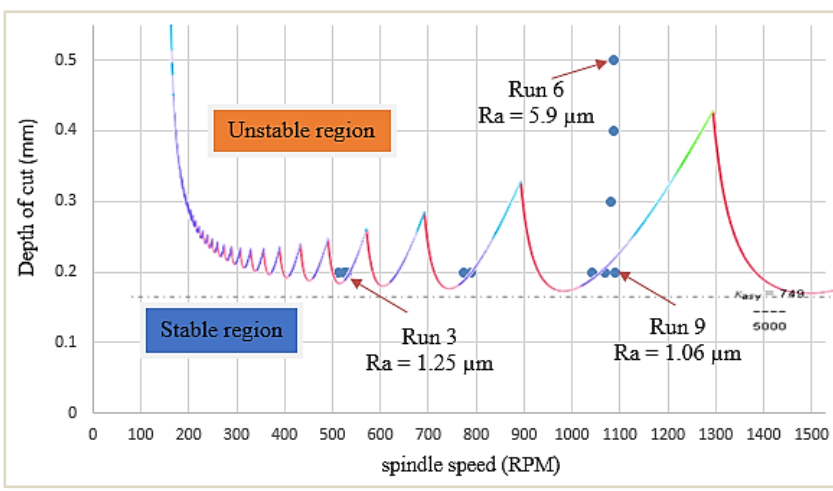

Fig. 6.Parameter comparison with both cutting tool and the chatter stability diagram maximum value.

In the comparison experiment, the stable region is on the low side of the lobe and the unstable region is located on the upper side of the lobe. Most of the experiment that produces high $R a$ value is located on the unstable region of the lobe. Fig. 7 shows the lowest value of $R a$ is located slightly on the lower region of the lobe.

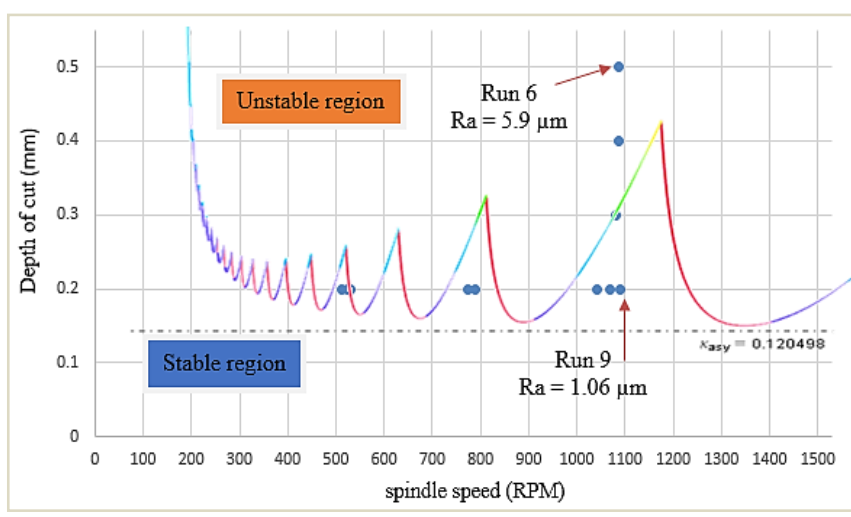

Fig. 7.Parameter comparison with both cutting tool and the chatter stability diagram minimum value.

In the comparison experiment for minimum value for the cutting tool, the stable region is also on the low side of the lobe and the unstable region is also located on the upper side of the lobe. Most of the experiment that produces high $R a$ and $R z$ values is located on the unstable region of the lobe. The lowest value of $R a$ and $R z$ are located slightly on the lower region of the lobe. There is slight deviation for these lobes where the input parameters for the chatter stability diagram are different from the cutting tool diagram maximum value parameters. The result is slightly deviated from the graph in Fig. 8.

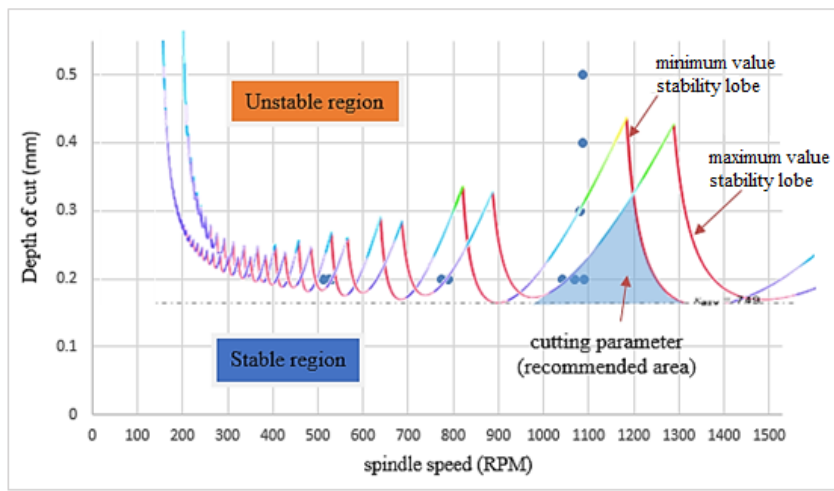

Fig. 8. Comparison of both chatter stability diagram for minimum and maximum value for the cutting tool.

Fig. 8 shows the comparison between the stability lobe diagram for the minimum value and the maximum value of the modal parameters. The comparison demonstrates an area for both lobes for the stable region. There is a small space for a suitable cutting condition for the P20 steel cutting based on the lobes as referred in Fig. 6. The cutting parameters that are appropriate based on the finding are: cutting speed is about $100 \mathrm{~m} / \mathrm{min}$, cutting depth is between $0.2 \mathrm{~mm}$ and $0.3 \mathrm{~mm}$, and the feed rate is between 0.03 $\mathrm{mm} / \mathrm{min}$ to $0.05 \mathrm{~mm} / \mathrm{min}$. 


\section{CONCLUSION}

The project's primary goals, according to all of the experiment, were to define the damping method in turning process and to investigate the method of low speed damping in this process. The following conclusions are drawn based on the outcomes in the method of machining P20 prehardened steel using distinct parameters condition throughout this experiment and to compare the process damping method with the chatter stability and surface roughness.

i. The experimental study demonstrates the impacts of cutting parameters on the surface roughness of P20 prehardened steel, specifically the cutting speed and feed rate. The combination of feed rate and cutting speed contributes a significant factor for dimensional precision that impacts the precision of the turning process. Feed rate is also an important factor that can affect surface roughness quality.

ii. The stable region is on the lobe's low side and the unstable region is on the lobe's top side. Most of the experiment producing an elevated value of $R a$ is located in the unstable region of the lobe. The smallest value of $R a$ is slightly reduced in the area of the lobe.

\section{ACKNOWLEDGMENT}

The authors would like to thank Universiti Putra Malaysia (grant GP/2017/9564400) for their support.

\section{REFERENCES}

1. P C. M. Taylor, S. Turner, and N. D. Sims, "Chatter, process damping, and chip segmentation in turning: A signal processing approach," Journal of Sound and Vibration, 329(23), 2010, pp. 4922-4935.

2. G. Kashyapi, S. Mohite, and N. Belwalkar, "Formation of Stability Lobe Diagram (SLD) for chatter free milling on aluminium alloy," Manufacturing Science and Technology, 3(2), 2015, pp. 32-37.

3. R. Samin, M. Z. Nuawi, S. M. Haris, and J. A. Ghani, "Correlation between chatter stability and integrated kurtosis-based algorithm for Z-filter (I-kazTM) coefficient in turning processes," Materials Today: Proceedings, 16, 2019, pp. 2128-2134.

4. G. Quintana and J. Ciurana, "Chatter in machining processes: A review," International Journal of Machine Tools and Manufacture, 51(5), 2011, pp. 363-376.

5. Y. Yamane, T. Ryutaro, S. Tadanori, I. M. Ramirez, and Y. Keiji, "A new quantitative evaluation for characteristic of surface roughness in turning," Precision Engineering, 50, 2017, pp. 20-26.

6. R. Samin, M. Z. Nuawi, S. M. Haris, and J. A. Ghani, "Stability analysis of regenerative vibration in turning operation using I-kaz3D signal processing approach," Journal of Physics: Conference Series, 1262(1), 2019, pp. $1-9$.

7. N. Badroush, C. H. Che Haron, J. A. Ghani, M. F. Azhar, and N. H. Abdul Halim, "Performance of coated carbide tools when turning inconel alloy 718 under cryogenic condition using RSM," Journal of Mechanical Engineering, 5(SI3), 2018, pp. 73-87.

8. J. Munoa, X. Beudaert, Z. Dombovari, Y. Altintas, E. Budak, C. Brecher, and G. Stepan, "Chatter suppression techniques in metal cutting," CIRP Annals, 65(2), 2016, pp. $785-808$.

9. A. Bagherzadeh and E. Budak, "Investigation of machinability in turning of difficult-to-cut materials using a new cryogenic cooling approach," Tribology International, 119, 2018, pp. 510-520.

10. M. S. Said, J. A. Ghani, R. Othman, M. A. Selamat, N N. Wan, and C. H. Che Hassan, "Surface roughness and chip formation of AlSi/AIN metal matrix composite by end milling machining using the Taguchi method," Jurnal Teknologi, 68(4), 2014, pp. 13-17.

11. M. S. Ruslan, K. Othman, J. A. Ghani, M. S. Kassim, and C. H. Che Haron, "Surface roughness of magnesium alloy AZ91D in high speed milling," Jurnal Teknologi, 78(6-9), 2016, pp. 115-119.

12. H. Azmi, C. H. Che Haron, J. A. Ghani, M. Suhaily, A B. Sanuddin, and J. H. Song, "Study on machinability effect of surface roughness in milling kenaf fiber reinforced plastic composite (unidirectional) using response surface methodology," ARPN J. Eng. Appl Sci., 11, 2016, pp. 4761-4766.

13. J. A. Ghani, M. N. A. M. Dali, H. A. Rahman, C. H. Che Haron, W. M. F. Wan Mahmood, M. R. Mohammad Rasani, and M. Z. Nuawi, "Analysis of dimple structure fabricated using turning process and subsequent reduction in friction," Wear, 426, 2019, pp. 1280-1285.

14. M. J. Reith and G. Stepan, "Effect of non-proportional damping on the dynamics and stability of multi-cutter turning systems," International Journal of Machine Tools and Manufacture, 117, 2017, pp. 23-30.

15. R. Kountanya, Chatter stability with orthogonal rotation. Wolfram Demonstration Project. 2014, [Online] Available:

http://demonstrations.wolfram.com/ChatterStabilityWith OrthogonalRotation/.

\section{AUTHORS PROFILE}

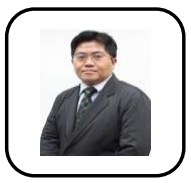

Razali Samin received his BEng (Hons) in Mechanical and Systems in 1996 and MSc in Robotics in 2002 from Universiti Putra Malaysia. He is currently a $\mathrm{PhD}$ student at Universiti Kebangsaan Malaysia and Senior Lecturer at Universiti Putra Malaysia. His current research interests include structural dynamics, machining dynamics, dynamics and control, robotics and automation, project risk and management

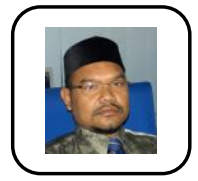

Mohd Zaki Nuawi is an Associated Professor at Universiti Kebangsaan Malaysis. He received a $\mathrm{BSc}$ (Hons) Industrial Engineering and $\mathrm{MSc}$ in Industrial Engineering from University in France, and $\mathrm{PhD}$ from Universiti Kebangsaan Malaysia. His current research includes acoustic and vibration, conditioned-based monitoring, applied ultrasonic and signal analysis.

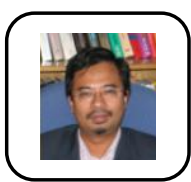

Sallehuddin Mohamed Haris is an Associated Professor at Universiti Kebangsaan Malaysia. He received his BEng in Manufacturing Systems Engineering from the University of Leeds, UK in 1993 MSc in Mechatronics from the University of London (King's College London) in 1996 and $\mathrm{PhD}$ in Electronics and Electrical Engineering from the University of Southampton, UK in 2006. His current research interests include adaptive and switching control systems, hybrid dynamic systems, and mechatronic systems for automotive and robotic applications.

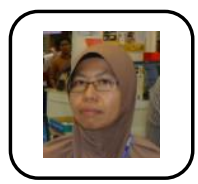

Jaharah A. Ghani is a Professor at Universit Kebangsaan Malaysia. She received her Beng (Hons) Manufacturing System Engineering from Leeds Polytechnic, Leeds, UK, in 1991, MSc Manufacturing System Engineering from Warwick University, UK in 1992 and PhD from University of Malaya, Malaysia in 2005. Her research interests include metal cutting, manufacturing process and system. 